\title{
Structure of lanthanum and cerium phosphate glasses by the method of isomorphic substitution in neutron diffraction
}

\author{
Richard A. Martin, ${ }^{1}$ Philip S. Salmon, ${ }^{1, *}$ Chris J. Benmore, ${ }^{2}$ Henry E. Fischer, ${ }^{3}$ and Gabriel J. Cuello ${ }^{4}$ \\ ${ }^{1}$ Department of Physics, University of Bath, Bath BA2 7AY, United Kingdom \\ ${ }^{2}$ IPNS, Argonne National Laboratory, 9700 South Cass Avenue, Argonne, Illinois 60126, USA \\ ${ }^{3}$ LURE, Centre Universitaire Paris-Sud, BP 34, F-91898, Orsay Cedex, France \\ ${ }^{4}$ Institut Laue-Langevin, BP 156, F-38042, Grenoble Cedex 9, France
}

(Received 14 April 2003; revised manuscript received 2 June 2003; published 8 August 2003)

\begin{abstract}
Neutron diffraction was used to measure the total structure factors for several rare-earth ion $R^{3+}\left(\mathrm{La}^{3+}\right.$ or $\mathrm{Ce}^{3+}$ ) phosphate glasses with composition close to $R \mathrm{Al}_{0.35} \mathrm{P}_{3.24} \mathrm{O}_{10.12}$. By assuming isomorphic structures, difference function methods were employed to separate, essentially, those correlations involving $R^{3+}$ from the remainder. A self-consistent model of the glass structure was thereby developed in which the $\mathrm{Al}$ correlations were taken into explicit account. The glass network was found to be made from interlinked $\mathrm{PO}_{4}$ tetrahedra having 2.2(1) terminal oxygen atoms, $\mathrm{O}_{\mathrm{T}}$, at 1.51(1) $\AA$, and 1.8(1) bridging oxygen atoms, $\mathrm{O}_{\mathrm{B}}$, at $1.60(1) \AA$. Rare-earth cations bonded to an average of 7.5(2) $\mathrm{O}_{\mathrm{T}}$ nearest neighbors in a broad and asymmetric distribution. The $\mathrm{Al}^{3+}$ ion acted as a network modifier and formed $\mathrm{O}_{\mathrm{T}}-\mathrm{Al}-\mathrm{O}_{\mathrm{T}}$ linkages that helped strengthen the glass. The connectivity of the $R$-centered coordination polyhedra was quantified in terms of a parameter $f_{s}$ and used to develop a model for the dependence on composition of the $\mathrm{Al}-\mathrm{O}_{\mathrm{T}}$ coordination number in $R$-Al-P-O glasses. By using recent ${ }^{17} \mathrm{Al}$ nuclear-magnetic-resonance data, it was shown that this connectivity decreases monotonically with increasing $\mathrm{Al}$ content. The chemical durability of the glasses appeared to be at a maximum when the connectivity of the $R$-centered coordination polyhedra was at a minimum. The relation of $f_{s}$ to the glass transition temperature, $T_{g}$, was discussed.
\end{abstract}

DOI: 10.1103/PhysRevB.68.054203

PACS number(s): 61.43.Fs, 81.05.Kf, 61.12.Ld

\section{INTRODUCTION}

Rare-earth ion phosphate glasses have many fascinating optoelectronic and magneto-optical properties which give them application as, for example, lasers and Faraday rotators. ${ }^{1-7}$ In order to develop realistic microscopic models to account for these phenomena, knowledge of the glass structure at the $\left(\right.$ Faber-Ziman $\left.{ }^{8}\right)$ partial structure factor level, $S_{\alpha \beta}(k)$, is required, where $k$ is the magnitude of the scattering vector. This presents, however, a challenging experimental task since samples prepared, e.g., by fusing $R \mathrm{P}_{3} \mathrm{O}_{9}$ in a platinum crucible comprise three chemical species and are described by six overlapping $S_{\alpha \beta}(k) .{ }^{9}$ Moreover, glasses with superior mechanical properties that enable fibers to be drawn, and which are also water resistant, can be prepared by fusing a suitable rare-earth oxide with $\mathrm{P}_{2} \mathrm{O}_{5}$ in an alumina crucible. ${ }^{10-12}$ There is, however, an attendant incorporation of $\mathrm{Al}$ into the structure ${ }^{11}$ which further complicates the problem through the introduction of an additional four $S_{\alpha \beta}(k)$.

A variety of techniques have been used to investigate the structure of rare-earth phosphate glasses prepared in alumina crucibles, including extended x-ray-absorption fine-structure spectroscopy, ${ }^{13-18}$ neutron diffraction, ${ }^{11}$ and $\mathrm{x}$-ray diffraction. ${ }^{12,13,19,20}$ Although trends associated with the lanthanide contraction ${ }^{21,22}$ have been observed, such as a shortening of the $R$-O nearest-neighbor distance, significant differences in the structural parameters have been reported. For example, $R-\mathrm{O}$ coordination numbers in the range 4.8(5)6.5(6) have been quoted for the same glass with (nominal) composition $\left(\mathrm{Ce}_{2} \mathrm{O}_{3}\right)_{0.235}\left(\mathrm{P}_{2} \mathrm{O}_{5}\right)_{0.765}$ together with $\mathrm{O}-(\mathrm{P})-\mathrm{O}$ coordination numbers in the range $3.4(3)-4.7(9),{ }^{11,12,16,18}$ where the latter notation refers to oxygen atoms interlinked by phosphorus. Unambiguous information on these parameters is, however, of basic importance: the $\mathrm{P}-\mathrm{O}$ and $\mathrm{O}-(\mathrm{P})-\mathrm{O}$ peak positions and coordination numbers give insight into the connectivity of the phosphate network, through the ratio of bridging oxygen sites, $\mathrm{O}_{\mathrm{B}}$, to terminal oxygen sites, $\mathrm{O}_{\mathrm{T}}$, on the $\mathrm{PO}_{4}$ tetrahedra, while the $R$-O coordination parameters help describe the degree of interlinking between $R$-centered polyhedra., ${ }^{9,23-26}$

The object of the present paper is to employ the method of isomorphic substitution in neutron diffraction, which has recently been used with success to study molten rare-earth compounds, ${ }^{27-30}$ to create difference functions that separate, essentially, those $S_{\alpha \beta}(k)$ involving rare-earth ions, $R^{3+}$, from the remainder. The experiments focus on glasses of composition similar to $\left(R_{2} \mathrm{O}_{3}\right)_{0.218}\left(\mathrm{Al}_{2} \mathrm{O}_{3}\right)_{0.076}\left(\mathrm{P}_{2} \mathrm{O}_{5}\right)_{0.706}$, or $R \mathrm{Al}_{0.35} \mathrm{P}_{3.24} \mathrm{O}_{10.12}$, which comprise $\mathrm{La}^{3+}$ or $\mathrm{Ce}^{3+}$ that are at the large cation radius end of the rare-earth series. These cations are chosen as isomorphic pairs since they are adjacent in the Periodic Table and have comparable cation radii $\left(1.16\right.$, cf. $1.14 \AA$ for eightfold coordination $\left.{ }^{31}\right)$ and Pettifor chemical parameters $(0.705$, cf. 0.7025$) .{ }^{32}$ They also share a similar structural chemistry, ${ }^{21,22}$ e.g., the crystalline orthophosphates of the large rare-earth ions, $c-R \mathrm{PO}_{4}$, have a common structure. ${ }^{33-35}$ Likewise, the crystalline metaphosphates, $c-R \mathrm{P}_{3} \mathrm{O}_{9}$, of the large rare-earth ions have a common structure, ${ }^{36,37}$ as do the crystalline ultraphosphates, $c-R \mathrm{P}_{5} \mathrm{O}_{14} \cdot 36,38-40$

The essential theory required to understand the diffraction results is first given in Sec. II. The sample preparation and characterization, together with the neutron-diffraction 
method, is then outlined in Sec. III. The results are presented in Sec. IV and, in the data analysis procedure, explicit account is taken of the $\mathrm{Al}$ correlations, by contrast with most previous diffraction and extended $\mathrm{x}$-ray-absorption finestructure studies in which the $\mathrm{Al}^{3+}$ was regarded as an impurity ion having a negligible impact on the measured patterns. ${ }^{11-19}$ Finally, in Sec. V, the results are discussed using the model of Hoppe and co-workers ${ }^{9,23-26}$ as a template. A method for calculating the connectivity of $R$-centered coordination polyhedra is also described, in which the results from neutron-diffraction and ${ }^{27} \mathrm{Al}$ nuclear-magneticresonance experiments are combined.

\section{THEORY}

In a neutron-diffraction experiment on an $R$-Al-P-O glass comprising a paramagnetic cation the differential scattering cross section per atom for unpolarized neutrons can be written as

$$
\left(\frac{d \sigma}{d \Omega}\right)_{t o t}=\left(\frac{d \sigma}{d \Omega}\right)_{\text {mag }}+\left(\frac{d \sigma}{d \Omega}\right)_{n u c l} .
$$

For the present materials, only $\mathrm{Ce}^{3+}$ exhibits paramagnetism and the corresponding differential scattering cross section $(d \sigma / d \Omega)_{m a g}$ was calculated in the free-ion approximation by using the scheme outlined in Ref. 27 . The nuclear differential scattering cross section is given by

$$
\left(\frac{d \sigma}{d \Omega}\right)_{n u c l}=F(k)+\sum_{\alpha} c_{\alpha}\left[b_{\alpha}^{2}+b_{i n c, \alpha}^{2}\right]\left[1+P_{\alpha}(k)\right],
$$

where $c_{\alpha}, b_{\alpha}$, and $b_{i n c, \alpha}$ denote the atomic fraction, coherent scattering length, and incoherent scattering length of chemical species $\alpha$, and $P_{\alpha}(k)$ is the corresponding inelasticity correction. ${ }^{41,42}$ The total structure factor is defined by

$$
F(k)=\sum_{\alpha} \sum_{\beta} c_{\alpha} c_{\beta} b_{\alpha} b_{\beta}\left[S_{\alpha \beta}(k)-1\right]
$$

and the accompanying real-space information is contained in the total pair-correlation function

$$
D(r)=\frac{4 \pi n_{0} r}{|G(0)|} G(r),
$$

where $n_{0}$ is the atomic number density,

$$
G(r)=\sum_{\alpha} \sum_{\beta} c_{\alpha} c_{\beta} b_{\alpha} b_{\beta}\left[g_{\alpha \beta}(r)-1\right],
$$

and the limiting value $G(0)$ follows from setting $g_{\alpha \beta}(0)$ $=0$ in Eq. (5). In a diffraction experiment this function is seldom obtained directly from the measured $F(k)$ because of the finite measurement window of the diffractometer $M(k$ $\left.\leqslant k_{\max }\right)=1, M\left(k>k_{\text {max }}\right)=0$ which is represented in real space by the symmetrical function

$$
M(r)=\frac{1}{\pi} \int_{0}^{k_{\max }} d k \cos (k r)=\frac{1}{\pi r} \sin \left(k_{\max } r\right) .
$$

Instead, the function $D^{\prime}(r)$ is obtained where

$$
D^{\prime}(r)=\frac{2}{\pi|G(0)|} \int_{0}^{\infty} d k F(k) k M(k) \sin (k r)=D(r) \otimes M(r)
$$

and $\otimes$ denotes the one-dimensional convolution operator. The normalization by $|G(0)|$ ensures that the weighting factors of the $g_{\alpha \beta}(r)$ in Eqs. (4) and (7) sum to unity such that the low- $r$ limit of $D(r)$ or $D^{\prime}(r)$ is given by $-4 \pi n_{0} r$.

To enable those features that are artifacts of $M(r)$ to be distinguished, each peak $i$ in $r g_{\alpha \beta}(r)$ can be represented by a Gaussian centered at $r_{\alpha \beta}(i)$ with standard deviation $\sigma_{\alpha \beta}(i)$ and an area corresponding to a coordination number, $\bar{n}_{\alpha}^{\beta}(i)$, of species $\beta$ around $\alpha$. The measured $D^{\prime}(r)$ can then be fitted by least squares to a sum of these Gaussians convoluted with $M(r)$ such that

$$
\begin{aligned}
D^{\prime}(r)= & \sum_{i}\left(\frac{W_{\alpha \beta}(i) \bar{n}_{\alpha}^{\beta}(i)}{\sqrt{2 \pi} c_{\beta}(i) r_{\alpha \beta}(i) \sigma_{\alpha \beta}(i)}\right. \\
& \left.\times \exp \left\{\frac{-\left[r-r_{\alpha \beta}(i)\right]^{2}}{2 \sigma_{\alpha \beta}^{2}(i)}\right\} \otimes M(r)\right)-4 \pi n_{0} r,
\end{aligned}
$$

where $\quad W_{\alpha \beta}(i)=c_{\alpha}^{2} b_{\alpha}^{2} /|G(0)| \quad$ if $\quad \alpha=\beta \quad$ and $\quad W_{\alpha \beta}(i)$ $=2 c_{\alpha} c_{\beta} b_{\alpha} b_{\beta} /|G(0)|$ if $\alpha \neq \beta$.

The complexity of correlations associated with $F(k)$ can be reduced by using difference function methods for glasses that are identical in every respect except for the scattering length of the rare-earth ions. If the structure factors measured for two glasses comprising rare-earth ions $R^{3+}$ and ' $R^{3+}$ with scattering lengths $b_{R}>b_{\prime_{R}}$ are denoted by ${ }^{R} F(k)$ and ${ }^{\prime} F(k)$, respectively, then those correlations not involving $R$ can be eliminated by forming the first-order difference function

$$
\Delta F_{R}(k)={ }^{R} F(k)-{ }^{\prime} F(k) .
$$

The corresponding real-space function is given by

$$
\Delta D_{R}^{\prime}(r)=\frac{4 \pi n_{0} r}{\left|\Delta G_{R}(0)\right|} \Delta G_{R}(r) \otimes M(r),
$$

where

$$
\begin{aligned}
\Delta G_{R}(r)= & { }^{R} G(r)-{ }^{\prime} R G(r)=c_{R}^{2}\left(b_{R}^{2}-b_{\prime_{R}}^{2}\right)\left[g_{R R}(r)-1\right] \\
& +\sum_{\alpha \neq R} 2 c_{R} c_{\alpha} b_{\alpha}\left(b_{R}-b{ }_{\prime_{R}}\right)\left[g_{R \alpha}(r)-1\right]
\end{aligned}
$$

and the limiting value $\Delta G_{R}(0)$ follows from setting all of the $g_{\alpha \beta}(0)=0$ in Eq. (11). The complexity of correlations associated with $F(k)$ can be further reduced by forming the difference function

$$
\Delta F(k)={ }^{R} F(k)-\frac{b_{R}}{b_{R}-b_{\prime_{R}}} \Delta F_{R}(k) .
$$

The $R$ - $\alpha$ correlations for $\alpha \neq R$ are thereby eliminated and the corresponding real-space function is given by 


$$
\Delta D^{\prime}(r)=\frac{4 \pi n_{0} r}{|\Delta G(0)|} \Delta G(r) \otimes M(r),
$$

where

$$
\begin{aligned}
\Delta G(r)= & { }^{R} G(r)-\frac{b_{R}}{b_{R}-b_{\prime_{R}}} \Delta G_{R}(r)=-c_{R}^{2} b_{R} b_{\prime_{R}}\left[g_{R R}(r)\right. \\
& -1]+\sum_{\alpha \neq R} \sum_{\beta \neq R} c_{\alpha} c_{\beta} b_{\alpha} b_{\beta}\left[g_{\alpha \beta}(r)-1\right]
\end{aligned}
$$

and the limiting value $\Delta G(0)$ follows from setting all of the $g_{\alpha \beta}(0)=0$ in Eq. (14). The normalization of the difference functions $\Delta D_{R}^{\prime}(r)$ and $\Delta D^{\prime}(r)$, by $\left|\Delta G_{R}(0)\right|$ and $|\Delta G(0)|$ in Eqs. (10) and (13), respectively, ensures that the weighting factors of the $g_{\alpha \beta}(r)$ sum to unity such that the low- $r$ limit in both cases is given by $-4 \pi n_{0} r$. Like for $D^{\prime}(r)$, the features in these difference functions that are artifacts of $M(r)$ can be identified by using a fitting procedure wherein each peak in $r g_{\alpha \beta}(r)$ is represented by a suitable Gaussian function.

If there is a small mismatch in the glass compositions, then $\Delta D_{R}^{\prime}(r)$ and $\Delta D^{\prime}(r)$ will be dominated by those correlations involved in Eqs. (10) and (13), respectively, but there will be an attendant contamination from unwanted $g_{\alpha \beta}(r)$. In this eventuality, the difference functions should offer an excellent guide to the glass structure although it is important to ensure that any models thus derived can account for the individually measured $D^{\prime}(r)$ and also for the total paircorrelation function measured for other glasses having a comparable composition.

\section{EXPERIMENT}

The samples required for the diffraction experiments were made by fusing $\mathrm{La}_{2} \mathrm{O}_{3}(99.9 \%), \mathrm{CeO}_{2}(99.9 \%)$, or an approximately $1: 2$ mixture of $\mathrm{La}_{2} \mathrm{O}_{3}$ and $\mathrm{CeO}_{2}$ with $\mathrm{P}_{2} \mathrm{O}_{5}$ $(99 \%)$ in alumina $\left(\mathrm{Al}_{2} \mathrm{O}_{3}\right)$ crucibles. The dry oxide powders were mixed in a ratio corresponding to $1 R: 5.67 \mathrm{P}$ which was chosen to ensure an excess of $\mathrm{P}_{2} \mathrm{O}_{5}$ relative to the metaphosphate composition, $\left(\mathrm{R}_{2} \mathrm{O}_{3}\right)_{0.25}\left(\mathrm{P}_{2} \mathrm{O}_{5}\right)_{0.75}$, much of which sublimes during the glass preparation procedure. The powder mixtures were initially allowed to absorb a fixed small amount of atmospheric water at room temperature before the crucible with its lid were placed into a preheated oven at $500{ }^{\circ} \mathrm{C}$ for $1 \mathrm{~h}$. The crucible was then moved to another oven heated to $1000^{\circ} \mathrm{C}$, left for $30 \mathrm{~min}$, and finally transferred to a third oven heated to $1620^{\circ} \mathrm{C}$. After $30 \mathrm{~min}$ the melt was poured into a graphite mould and annealed at $500{ }^{\circ} \mathrm{C}$ for 24 $\mathrm{h}$. The resultant glassy samples, of mass $\approx 16 \mathrm{~g}$, were transparent, free from bubbles, and visibly homogeneous. The $\mathrm{Ce}^{3+}$ oxidation state in phosphate glasses prepared using a similar procedure has previously been confirmed by magnetic-susceptibility experiments. ${ }^{43}$

Although all of the glasses were prepared using an identical method, the crucibles were not sealed and the process by which the $\mathrm{Al}$ was incorporated into the glassy matrix was difficult to control. This precluded the use of expensive rareearth isotopes and application of the isotopic substitution method in neutron diffraction. ${ }^{44-46}$ Instead, many samples were made with the aim of selecting those with matching compositions after investigation using electron probe microanalysis. In the latter experiments, a cross section was taken through each sample to examine the bulk material at several points and the glass composition was thereby found to be microscopically homogeneous. Factors aiding sample homogeneity are, presumably, the use of a small sample volume, which gives rise to a large contact area between the melt and crucible surface, and the fluidity of the melt at the high temperatures utilized, which helps to distribute the alumina dissolved at the crucible surface throughout the bulk material.

By comparison with phosphate glasses containing small rare-earth cations, ${ }^{47,48}$ samples with a relatively large distribution of compositions were prepared. Nevertheless, the compositions were similar and the glasses $\mathrm{LaAl}_{0.36(1)} \mathrm{P}_{3.32(1)} \mathrm{O}_{10.25(3)}, \quad \mathrm{LaAl}_{0.31(2)} \mathrm{P}_{3.10(6)} \mathrm{O}_{9.70(41)}$, and ${ }^{\text {mix }} R \mathrm{Al}_{0.38(5)} \mathrm{P}_{3.31(8)} \mathrm{O}_{10.40(23)}$, where ${ }^{\text {mix }} R$ corresponds to a 1:1.14 mixture of $\mathrm{La}$ and $\mathrm{Ce}$, were chosen for further investigation. For brevity of notation they are henceforth referred to as $\mathrm{La} A, \mathrm{La} B$, and $\mathrm{LaCe}$. The mass density was determined by measuring the sample weight in fluids of different density, and $n_{0}=0.0701(3) \AA^{-3}$ was thereby deduced for each of the glasses.

The neutron-diffraction experiments were performed using either the D4C instrument at the Institut Laue-Langevin (Grenoble), with an incident neutron wavelength of 0.7100 $\AA$, or the GLAD instrument at the Intense Pulsed Neutron Source, Argonne National Laboratory. The coarsely powdered samples were held at ambient temperature $\left(\approx 25^{\circ} \mathrm{C}\right)$ in cylindrical vanadium cans of either 6.8 - $\mathrm{mm}$ internal diameter and $0.1-\mathrm{mm}$ wall thickness (D4C) or 9.27-mm internal diameter and 0.127-mm wall thickness (GLAD). Diffraction patterns were taken for the samples in their container, the empty container, and a vanadium rod of dimensions comparable to the sample for normalization purposes. The intensity for a cadmium neutron-absorbing rod of similar diameter to the sample was also measured on D4C to account for the effect of sample self-shielding on the background count rate at small scattering angles. ${ }^{49}$ Each complete diffraction pattern was built up from the intensities measured for the different detector groups. These intensities were saved at regular intervals and no deviation among them was observed, apart from the expected statistical variations, which verified the diffractometer stability. ${ }^{50}$ The total paramagnetic scattering cross section of $\mathrm{Ce}^{3+}$ at the incident neutron wavelength was calculated using the method given in Ref. 27 and the data analysis followed the procedure described elsewhere. $^{27,45}$ The coherent neutron scattering lengths $b_{\mathrm{La}}$ $=8.24(4), b_{\mathrm{Ce}}=4.84(2), b_{\mathrm{Al}}=3.449(5), b_{\mathrm{P}}=5.13(1)$, and $b_{\mathrm{O}}=5.803(4) \mathrm{fm}$ were taken from Sears ${ }^{51}$ and the weighting factors for the $g_{\alpha \beta}(r)$ appearing in Eqs. (5), (11), and (14) are given in Table I.

\section{RESULTS}

The total structure factors for $\mathrm{La} A$, measured using GLAD, and $\mathrm{La} B$ and $\mathrm{LaCe}$, measured using D4C, are shown in Fig. 1. There is good overall agreement between each 
TABLE I. Weighting factors (in millibarn) for the $g_{\alpha \beta}(r)$ in the $r$-space functions $G(r), \Delta G_{R}(r)$, and $\Delta G(r)$ given by Eqs. (5), (11), and (14), respectively. The difference functions were formed from the data sets for the $\mathrm{La} B$ and $\mathrm{LaCe}$ glasses and the limiting values $|G(0)|$, $\left|\Delta G_{R}(0)\right|$, and $|\Delta G(0)|$ were obtained by summing all of the weighting factors for the corresponding $g_{\alpha \beta}(r)$.

\begin{tabular}{|c|c|c|c|c|c|c|c|c|c|c|}
\hline & $g_{R R}(r)$ & $g_{R \mathrm{P}}(r)$ & $g_{R \mathrm{O}}(r)$ & $g_{R \mathrm{Al}}(r)$ & $g_{\mathrm{PP}}(r)$ & $g_{\mathrm{PO}}(r)$ & $g_{\mathrm{PAl}}(r)$ & $g_{\mathrm{OO}}(r)$ & $g_{\mathrm{AlO}}(r)$ & $g_{\mathrm{AlAl}}(r)$ \\
\hline${ }^{\mathrm{La} A} G(r)$ & $3.05(3)$ & $12.59(7)$ & $44.0(2)$ & $0.917(5)$ & $13.01(5)$ & $91.0(2)$ & $1.896(5)$ & $158.7(2)$ & $6.62(1)$ & $0.0690(2)$ \\
\hline${ }^{\mathrm{La} B} G(r)$ & $3.41(3)$ & $13.16(7)$ & $46.6(2)$ & $0.873(4)$ & $12.71(5)$ & $90.0(2)$ & $1.685(4)$ & $159.3(2)$ & $5.97(1)$ & $0.0559(2)$ \\
\hline${ }^{\mathrm{LaCe}} G(r)$ & $1.82(1)$ & $9.60(4)$ & $34.1(1)$ & $0.747(3)$ & $12.68(5)$ & $90.0(2)$ & $1.976(5)$ & $159.8(2)$ & 7.01(1) & $0.0769(2)$ \\
\hline$\Delta G_{R}(r)$ & $1.59(3)$ & $3.57(8)$ & $12.6(3)$ & $0.125(5)$ & $0.02(7)$ & $-0.1(3)$ & $-0.291(6)$ & $-0.5(3)$ & $-1.05(1)$ & $-0.0211(3)$ \\
\hline$\Delta G(r)$ & $-3.9(2)$ & $-3.1(4)$ & $-11(1)$ & $0.30(2)$ & $12.6(3)$ & $90(1)$ & $3.01(3)$ & 161(1) & $10.73(7)$ & $0.152(1)$ \\
\hline
\end{tabular}

$F(k)$ and the back-Fourier transform of the corresponding total pair-correlation function $D^{\prime}(r)$, after the unphysical low- $r$ oscillations are set to their calculated limit of $-4 \pi n_{0} r$ (see Fig. 2), which indicates that the data correction procedures have been properly applied. ${ }^{45}$ The GLAD data extends to a larger $k_{\max }$ of $24.95 \AA^{-1}$, such that the modification function $M(r)$ will have a smaller broadening effect on the corresponding $D(r)$, while the D4C data have smaller statistical errors and $k_{\max }=15.65 \AA^{-1}$.

The difference functions $\Delta F_{R}(k)$ and $\Delta F(k)$ of Fig. 3 were formed by using the D4C data and the corresponding $\Delta D_{R}^{\prime}(r)$ and $\Delta D^{\prime}(r)$ are shown in Fig. 2. Inspection of Table I shows that while these functions are dominated by the desired $g_{\alpha \beta}(r)$, there is a small contamination from unwanted correlations owing to a small mismatch in sample compositions. An analysis strategy was therefore adopted in which the effect of these unwanted correlations was taken into explicit account. First, $\Delta D_{R}^{\prime}(r)$ was modeled using the Gaussian fitting procedure outlined in Sec. II. The fitted parameters thus obtained were then used as a starting point for modeling the main unwanted correlations in a fit to $\Delta D^{\prime}(r)$. In turn, these fitted parameters were used as a starting point for modeling the main unwanted correlations in a further fit

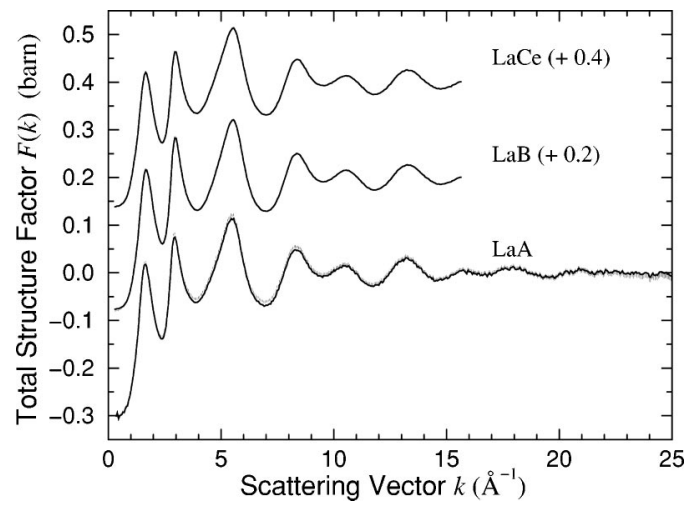

FIG. 1. The measured total structure factors $F(k)$ for the $\mathrm{LaAl}_{0.36} \mathrm{P}_{3.32} \mathrm{O}_{10.25}, \quad \mathrm{LaAl}_{0.31} \mathrm{P}_{3.10} \mathrm{O}_{9.70}$, and ${ }^{m i x} R \mathrm{Al}_{0.38} \mathrm{P}_{3.31} \mathrm{O}_{10.40}$ glasses denoted by $\mathrm{La} A, \mathrm{La} B$, and $\mathrm{LaCe}$, respectively. The data are represented by the points with error bars and the solid curves are the back-Fourier transforms of the corresponding $D^{\prime}(r)$ after the unphysical low- $r$ oscillations are set to the calculated limit of $-4 \pi n_{0} r$ (see Fig. 2). For the $\mathrm{La} B$ and $\mathrm{LaCe}$ data sets the backFourier transforms are almost indistinguishable from the data points on the plot scale. to $\Delta D_{R}^{\prime}(r)$. The entire process was iterated until selfconsistent parameters were obtained for the fits to both $r$-space functions. Finally, the reliability of the model thus produced was tested by fitting the individual $D^{\prime}(r)$ for all of the investigated $R$-Al-P-O glasses.

The results of the Gaussian fitting procedure for $\Delta D_{R}^{\prime}(r)$, $\Delta D^{\prime}(r)$, and $D^{\prime}(r)$ are shown in Figs. 4-6, respectively and the fitted parameters are given in Tables II and III. In general, the peaks fitted at the larger- $r$ values are not expected to yield accurate parameters, owing to the overlap from correlations at even larger $r$, but were included to increase the reliability of the parameters that are reported for the peaks fitted at smaller $r$. The structures of $c-\mathrm{LaP}_{3} \mathrm{O}_{9},{ }^{37}$ $c$ - $\mathrm{LaP}_{5} \mathrm{O}_{14},{ }^{40}$ and $c-\mathrm{LaPO}_{4}$ (Ref. 35) were used as a guide for assigning the individual peaks in the difference functions.

In $c-\mathrm{LaP}_{3} \mathrm{O}_{9}$ the shortest La-O, La-(O)-P, and La-La distances are $2.42,3.29$, and $4.32 \AA$, respectively, and the shortest second-nearest-neighbor La-O distance is $3.97 \AA$, ${ }^{37}$ where La-(O)-P denotes La and $\mathrm{P}$ interlinked by $\mathrm{O}$. The corresponding distances are $2.46,3.67,5.25$, and $4.26 \AA$ for $c-\mathrm{LaP}_{5} \mathrm{O}_{14}$ (Ref. 40) and 2.47, 3.22, 4.10, and $3.17 \AA$ for $c$ - $\mathrm{LaPO}_{4},{ }^{35}$ respectively. The first peak in $\Delta D_{R}^{\prime}(r)$ at 2.50(2) $\AA$ was therefore assigned to $R-\mathrm{O}$ correlations and the region immediately beyond $3.2 \AA$ to $R$ - $(\mathrm{O})$-P correlations. For the first peak, there are no well-defined distances having Gauss-

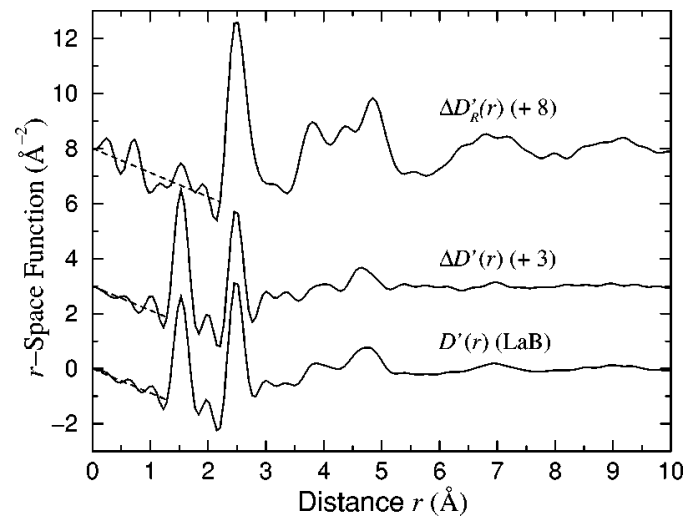

FIG. 2. The total pair-correlation function $D^{\prime}(r)$ for glassy $\mathrm{La} B$, obtained by Fourier transforming the total structure factor given in Fig. 1, together with the difference functions $\Delta D_{R}^{\prime}(r)$ and $\Delta D^{\prime}(r)$, obtained by Fourier transforming the difference functions $\Delta F_{R}(k)$ and $\Delta F(k)$ given in Fig. 3. The calculated low- $r$ limit of all these functions is equal to $-4 \pi n_{0} r$ and is shown by the dashed curves. 


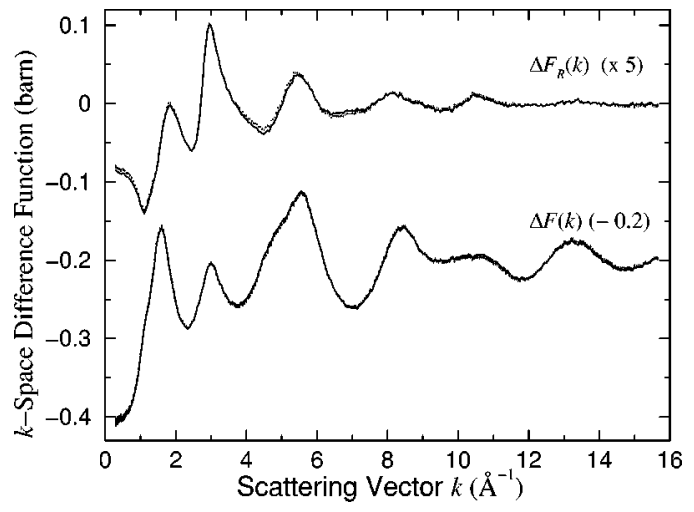

FIG. 3. The points with error bars give the difference functions $\Delta F_{R}(k)$ (scaled by a factor of 5) and $\Delta F(k)$ obtained by applying Eqs. (9) and (12) to the $F(k)$ for glassy $\mathrm{La} B$ and $\mathrm{LaCe}$. The solid curves are the back-Fourier transforms of the corresponding $\Delta D_{R}^{\prime}(r)$ and $\Delta D^{\prime}(r)$, given in Fig. 2, after the unphysical low- $r$ oscillations are set to the calculated limit of $-4 \pi n_{0} r$.

ian distributions. Rather, there is a broad distribution of $R-\mathrm{O}$ distances that could best be modeled using four Gaussians positioned in the range 2.46-3.09 $\AA$, giving an overall $R$-O coordination number of $\bar{n}_{R}^{\mathrm{O}}=7.5$ (2) (Table II). The second peak was modeled using the structure of $c-\mathrm{LaP}_{3} \mathrm{O}_{9}$ as a starting point and the overall fit for the range $2.0 \leqslant r(\AA) \leqslant 3.5$ gave a goodness-of-fit parameter $R_{\chi}$ (Ref. 52) of $2.1 \%$. As shown in Fig. 4, the contribution to $\Delta D_{R}^{\prime}(r)$ from unwanted correlations is small. The veracity of the overall $R-\mathrm{O}$ coordination number was confirmed by direct integration of the first peak in $\Delta D_{R}^{\prime}(r)$ from 2.21 to $3.22 \AA$, whereupon a coordination number of $\bar{n}_{R}^{\mathrm{O}}=7.5(2)$ was also obtained.

By comparison with the glass, in $c-\mathrm{LaP}_{3} \mathrm{O}_{9}$ and $c-\mathrm{LaP}_{5} \mathrm{O}_{14}$ there are eight $R-\mathrm{O}$ nearest neighbors distributed over the ranges $2.42-2.75$ and 2.46-2.55 $\AA$, respectively, ${ }^{37,40}$ i.e., the $R-\mathrm{O}$ coordination environment in the glassy phase has a more asymmetric distribution. This

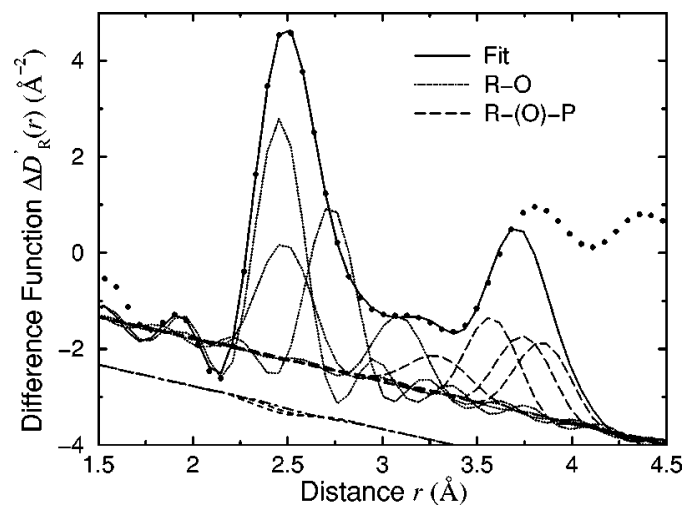

FIG. 4. The filled circles give the difference function $\Delta D_{R}^{\prime}(r)$ obtained by Fourier transforming $\Delta F_{R}(k)$ given by the points with error bars in Fig. 3. The solid curve gives the fitted function and the other curves the individual convoluted Gaussians: $R-O$ (dotted curves) and $R-(\mathrm{O})-\mathrm{P}$ (long dashed curves). There is a small contamination of $\Delta D_{R}^{\prime}(r)$ by unwanted $\mathrm{O}-\mathrm{O}$ correlations which are shown by dashed curves displaced by $-1 \AA^{-2}$ (see the text).

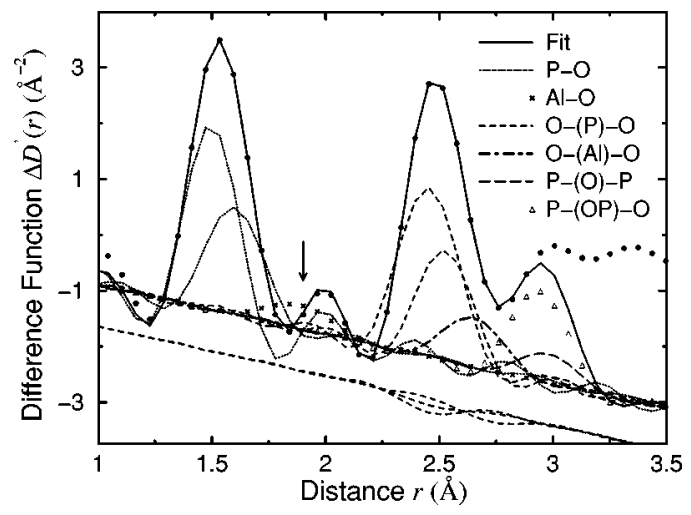

FIG. 5. The filled circles give the difference function $\Delta D^{\prime}(r)$ obtained by Fourier transforming $\Delta F(k)$ given by the points with error bars in Fig. 3. The solid curve gives the fitted function and the other curves the individual convoluted Gaussians: P-O (dotted curves), Al-O (crossed curve), O-(P)-O (dashed curves), O-(Al)-O (dot-dashed curve), P-(O)-P (long-dashed curve), and P-(OP)-O (curve with triangles). The vertical arrow shows the position of the Al-O peak. There is a small contamination of $\Delta D^{\prime}(r)$ by unwanted $R$-O correlations which are shown by dashed curves displaced by $-0.75 \AA^{-2}$ (see the text).

observation is consistent with the neutron- and $\mathrm{x}$-raydiffraction study of Hoppe et al..$^{9,53}$ on glassy $\mathrm{LaP}_{3} \mathrm{O}_{9}$ in which a better representation of their data was obtained by assuming an asymmetric distribution of $R$-O nearestneighbor correlations with $\bar{n}_{\mathrm{La}}^{\mathrm{O}}=7.2(5)$, although the spread of distances was smaller at 2.45-2.55 $\AA$. A similar scenario, with $\bar{n}_{\mathrm{Eu}}^{\mathrm{O}}=7.7(3)$ in the range $2.30-2.83 \AA$, was also deduced for a glass with nominal composition $\mathrm{EuP}_{3} \mathrm{O}_{9}$ from the X-ray-diffraction study of Cannas et al. ${ }^{20}$

In $c-\mathrm{LaP}_{3} \mathrm{O}_{9}$ the shortest $\mathrm{P}-\mathrm{O}, \mathrm{O}-(\mathrm{P})-\mathrm{O}$, and $\mathrm{P}-(\mathrm{O})-\mathrm{P}$ distances are $1.47,2.45$, and $2.98 \AA$, respectively, ${ }^{37}$ where $\mathrm{O}-(\mathrm{P})-\mathrm{O}$ denotes oxygen atoms interlinked by phosphorus and $\mathrm{P}-(\mathrm{O})-\mathrm{P}$ denotes phosphorus atoms interlinked by oxygen, and the corresponding distances are 1.46, 2.39, and 2.90 $\AA$ for $c-\mathrm{LaP}_{5} \mathrm{O}_{14} \cdot{ }^{40} \mathrm{In} c-\mathrm{LaPO}_{4}$ the $\mathrm{PO}_{4}$ tetrahedra are isolated, i.e., they do not share oxygen atoms, and the P-O, $\mathrm{O}-(\mathrm{P})-\mathrm{O}$, and P-P distances are 1.52, 2.44, and $4.05 \AA$, respectively. ${ }^{35}$ The first peak in $\Delta D^{\prime}(r)$ at $1.54(2) \AA$ was therefore assigned to the $\mathrm{P}-\mathrm{O}$ correlations from $\mathrm{PO}_{4}$ tetrahedra and the corresponding $\mathrm{O}-(\mathrm{P})-\mathrm{O}$ correlations give a strong contribution to the second peak at 2.49(2) $\AA$. The region between these two peaks, $1.7 \leqslant r(\AA) \leqslant 1.9$, has a contribution from Al-O correlations since ${ }^{27} \mathrm{Al}$ nuclear-magneticresonance (NMR) experiments, made on rare-earth phosphate glasses prepared in alumina crucibles, ${ }^{11,54}$ show that $\mathrm{Al}$ can be fourfold, fivefold, or six-fold coordinated to oxygen. In $c-\mathrm{AlP}_{3} \mathrm{O}_{9},{ }^{55}$ aluminum is octahedrally coordinated to oxygen at a distance $r_{\mathrm{AlO}}=1.88 \AA$ giving an $\mathrm{O}-(\mathrm{Al})-\mathrm{O}$ nearestneighbor separation of $\sqrt{2} r_{\mathrm{AlO}}=2.66 \AA$, placing these correlations under the second peak in $\Delta D^{\prime}(r)$. By comparison, for tetrahedral coordination $r_{\mathrm{AlO}}=1.76 \AA$, ${ }^{56}$ giving an $\mathrm{O}$-(Al)-O distance of $\sqrt{8 / 3} r_{\mathrm{AlO}}=2.87 \AA$ in the region between the second and third peaks in $\Delta D^{\prime}(r)$. The second peak has, therefore, contributions only from $\mathrm{O}-(\mathrm{P})-\mathrm{O}$ and $\mathrm{O}-(\mathrm{Al})-\mathrm{O}$ correlations while the third peak was modeled as- 

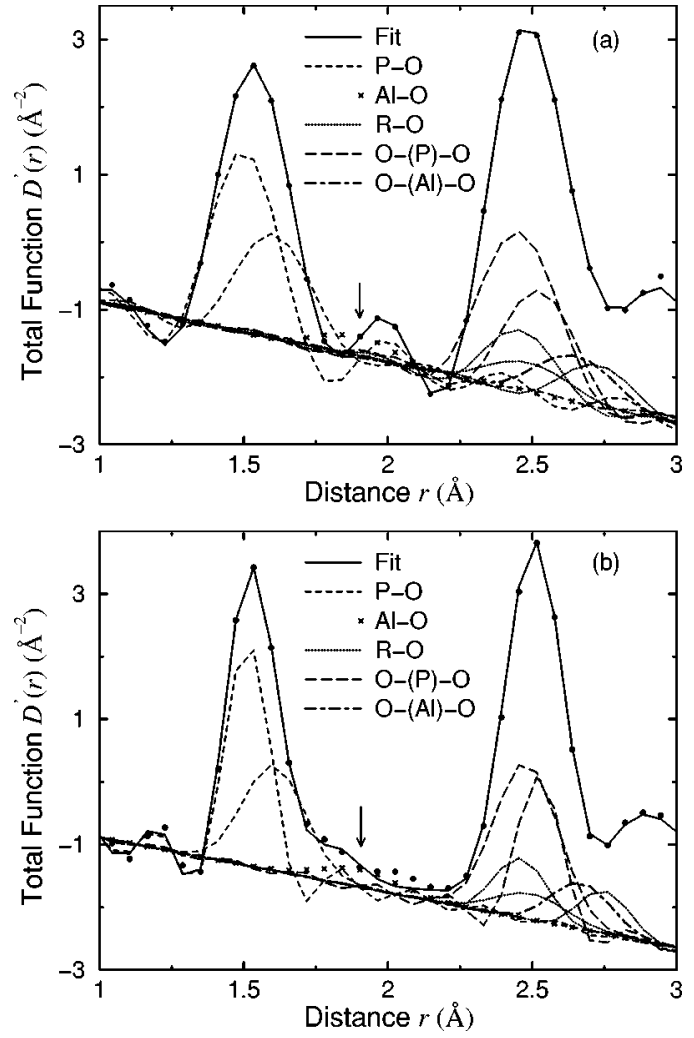

FIG. 6. The filled circles give the total pair-correlation functions $D^{\prime}(r)$ for the (a) $\mathrm{La} B$ and (b) $\mathrm{La} A$ glasses obtained by Fourier transforming the total structure factors given in Fig. 1. The solid curves give the fitted functions and the other curves the individual convoluted Gaussians: P-O (dashed curves), Al-O (crossed curve), $R$-O (dotted curves), O-(P)-O (long-dashed curves), and O-(Al)-O (dot-dashed curve). The vertical arrow shows the position of the Al-O peak. Several of the larger- $r$ Gaussians are omitted for clarity of presentation.

suming $\mathrm{P}-(\mathrm{OP})-\mathrm{O}$ and $\mathrm{P}-(\mathrm{O})-\mathrm{P}$ correlations using the structure of $c-\mathrm{LaP}_{3} \mathrm{O}_{9}$ (Ref. 37) as a starting point.

The fit to $\Delta D^{\prime}(r)$ over the range $1.3 \leqslant r(\AA) \leqslant 2.9$ gave $R_{\chi}=1.6 \%$ and, as shown in Fig. 5, the contribution from unwanted correlations is small. Two Gaussians were used to represent the first peak, with $\bar{n}_{\mathrm{P}}^{\mathrm{O}_{\mathrm{T}}}=2.2(1)$ at $1.50(1) \AA$ and $\bar{n}_{\mathrm{P}} \mathrm{O}_{\mathrm{B}}=1.7(1)$ at $1.60(1) \AA$, giving an overall $\mathrm{P}-\mathrm{O}$ coordination number $\bar{n}_{\mathrm{P}}^{\mathrm{O}}=3.9(1)$. These values for the $\mathrm{P}-\mathrm{O}_{\mathrm{T}}$ and $\mathrm{P}-\mathrm{O}_{\mathrm{B}}$ bond lengths are typical of those found in other rareearth phosphate glasses of similar composition ${ }^{9,11,26}$ and a peak width for $\mathrm{P}-\mathrm{O}_{\mathrm{B}}$ that is broader than that for $\mathrm{P}-\mathrm{O}_{\mathrm{T}}$ is a typical feature of phosphate glasses. ${ }^{25}$ A distance $r_{\mathrm{AlO}}$ $=1.89(3) \AA$ was found, in accord with Refs. 11,12, and 20, with $\bar{n}_{\mathrm{Al}}^{\mathrm{O}}=4.5(5)$. The second peak was fitted with Gaussians centered at 2.46(1), 2.53(1), and 2.65(1) $\AA$ corresponding to $\mathrm{O}-(\mathrm{P})-\mathrm{O}$ coordination numbers of 2.5(1) and 1.5(1) and an $\mathrm{O}-(\mathrm{Al})-\mathrm{O}$ coordination number of $0.8(1)$, respectively, i.e., the overall $\mathrm{O}-(\mathrm{P})-\mathrm{O}$ nearest-neighbor coordination number $\bar{n}_{\mathrm{O}}^{\mathrm{O}}=4.0(1)$. A single Gaussian fit to the $\mathrm{O}-(\mathrm{P})-\mathrm{O}$ correlations under the second peak was found to be inadequate, giving a higher $R_{\chi}$ value of $2.5 \%$, and the use of two Gaussians to represent the $\mathrm{O}-(\mathrm{P})-\mathrm{O}$ correlations was also found to be necessary for $R$-Al-P-O glasses containing small rare-earth ions. ${ }^{48}$ The small peak at $2 \AA$ was found to be mostly an artifact of $M(r)$.

The self-consistent parameters obtained from the Gaussian fits to $\Delta D_{R}^{\prime}(r)$ and $\Delta D^{\prime}(r)$ were used as starting parameters for fits to the $D^{\prime}(r)$ (see Fig. 6). These gave $R_{\chi}$ values of $4.9 \%, 1.5 \%$, and $1.7 \%$ for the range $1.2 \leqslant r(\AA) \leqslant 2.8$ in the case of the $\mathrm{La} A, \mathrm{La} B$, and $\mathrm{LaCe}$ glasses, respectively. As shown from a comparison of Tables II and III, comparable peak positions and coordination numbers were obtained, although the $D^{\prime}(r)$ functions were best represented using a larger $\mathrm{Al}-\mathrm{O}$ coordination number $\bar{n}_{\mathrm{Al}}^{\mathrm{O}} \approx 6$. The larger $R_{\chi}$ value for the GLAD data can be attributed to an inadequate fit in the region $2.0 \leqslant r(\AA) \leqslant 2.2$, the reason for which could not be traced definitively [cf. Figs. 6(a) and 6(b)]. Nevertheless, the peak positions and coordination numbers obtained from the fits to the $D^{\prime}(r)$ functions for all of the glasses are the same within experimental error.

\section{DISCUSSION}

In crystalline and glassy $\mathrm{P}_{2} \mathrm{O}_{5}$, a network is built from corner-sharing $\mathrm{PO}_{4}$ tetrahedra comprising one terminal oxygen atom, $\mathrm{O}_{\mathrm{T}}$, and three bridging oxygen atoms, $\mathrm{O}_{\mathrm{B}}$, at distances close to 1.4 and $1.6 \AA$, respectively. ${ }^{6,57-61}$ In the model of Hoppe and co-workers, ${ }^{9,23-26}$ the addition of a network modifier such as $R_{2} \mathrm{O}_{3}$ leaves the $\mathrm{PO}_{4}$ tetrahedra intact but depolymerizes the phosphate network through the breakage of $\mathrm{P}_{-} \mathrm{O}_{\mathrm{B}}-\mathrm{P}$ bonds, thereby increasing the fraction of $\mathrm{O}_{\mathrm{T}}$ to which the $R^{3+}$ ions are exclusively bound via $\mathrm{P}_{-} \mathrm{O}_{\mathrm{T}}-R$ linkages. Specifically, if $y$ oxygen atoms from the network modifier are added per $\mathrm{P}_{2} \mathrm{O}_{5}$ unit, the $\mathrm{P}: \mathrm{O}_{\mathrm{B}}: \mathrm{O}_{\mathrm{T}}$ ratio changes from 2:3:2 in pure $\mathrm{P}_{2} \mathrm{O}_{5}$ to $2:(3-y): 2(1+y)$ in the modified material. The expressions $\bar{n}_{\mathrm{O}_{\mathrm{B}}}^{\mathrm{O}}=6(3-y) /(5+y)$ and $\bar{n}_{\mathrm{O}_{\mathrm{T}}}^{\mathrm{O}}$ $=6(1+y) /(5+y)$ then follow from taking oxygen-oxygen coordination numbers of 6 and 3 for the $\mathrm{O}_{\mathrm{B}}$ and $\mathrm{O}_{\mathrm{T}}$ sites, respectively, giving an overall $\mathrm{O}-(\mathrm{P})-\mathrm{O}$ nearest-neighbor coordination number of $\bar{n}_{\mathrm{O}}^{\mathrm{O}}=24 /(5+y)$. The nearest-neighbor $\mathrm{P}-\left(\mathrm{O}_{\mathrm{B}}\right)-\mathrm{P}$ coordination number is given by $\bar{n}_{\mathrm{P}}^{\mathrm{P}}=3-y$.

In the case of $R$-Al-P-O compounds it can be readily shown that $y=2 c_{\mathrm{O}} / c_{\mathrm{P}}-5$, provided $\mathrm{Al}$ acts as a network modifier, and it then follows that the $R: \mathrm{O}_{\mathrm{T}}$ ratio is given by $1: 2\left[c_{\mathrm{O}}-2 c_{\mathrm{P}}\right] / c_{R}$. When $\mathrm{Al}$ is absent, the composition can be written as $\left(R_{2} \mathrm{O}_{3}\right)_{x}\left(\mathrm{P}_{2} \mathrm{O}_{5}\right)_{1-x}$, where $x$ is $1 / 2,1 / 4$, or $1 / 6$ for the orthophosphates, metaphosphates, and ultraphosphates, respectively, in which the case $y=3 x /(1-x)$ and the $R: \mathrm{O}_{\mathrm{T}}$ ratio becomes $1:(1+2 x) / x .{ }^{26}$ Hence $\mathrm{O}-(\mathrm{P})-\mathrm{O}$ coordination numbers, which are in agreement with the observed values for several crystalline $R-\mathrm{P}-\mathrm{O}$ systems, can be calculated: $\bar{n}_{\mathrm{O}}^{\mathrm{O}}$ is 4.8 for $c-\mathrm{P}_{2} \mathrm{O}_{5},{ }^{22,60,61} 4.29$ for $c-R \mathrm{P}_{5} \mathrm{O}_{14},{ }^{36,40} 4.0$ for $c-R \mathrm{P}_{3} \mathrm{O}_{9},{ }^{36,37}$ and 3.0 for $R \mathrm{PO}_{4} \cdot{ }^{35}$ Furthermore, in the metaphosphate and ultraphosphate crystalline phases of large rare-earth ions, $R^{3+}$ is bound to eight $\mathrm{O}_{\mathrm{T}}$ while the number of $\mathrm{O}_{\mathrm{T}}$ atoms available per cation is six and eight, respectively. None of the bonded $\mathrm{O}_{\mathrm{T}}$ need, therefore, to be shared between the $R$-centered coordination polyhedra in the case of 
TABLE II. Parameters obtained from the Gaussian fits to the $\Delta D_{R}^{\prime}(r)$ and $\Delta D^{\prime}(r)$ difference functions formed from the data sets for the $\mathrm{La} B$ and $\mathrm{LaCe}$ glasses.

\begin{tabular}{|c|c|c|c|c|c|c|}
\hline & $\begin{array}{l}\Delta D_{R}^{\prime}(r) \\
r_{\alpha \beta}(\AA)\end{array}$ & $\bar{n}_{\alpha}^{\beta}$ & $\sigma_{\alpha \beta}(\AA)$ & $\begin{array}{l}\Delta D^{\prime}(r) \\
r_{\alpha \beta}(\AA)\end{array}$ & $\bar{n}_{\alpha}^{\beta}$ & $\sigma_{\alpha \beta}(\AA)$ \\
\hline $\mathrm{P}-\mathrm{O}_{\mathrm{T}}$ & & & & $1.50(1)$ & $2.2(1)$ & $0.05(1)$ \\
\hline $\mathrm{P}-\mathrm{O}_{\mathrm{B}}$ & & & & $1.60(1)$ & $1.7(1)$ & $0.10(1)$ \\
\hline $\mathrm{Al}-\mathrm{O}$ & & & & $1.89(3)$ & $4.5(5)$ & $0.13(1)$ \\
\hline$R-\mathrm{O}$ & $2.46(1)$ & $2.6(1)$ & $0.07(1)$ & $2.46(1)$ & $2.6(1)$ & $0.07(1)$ \\
\hline$R-\mathrm{O}$ & $2.49(1)$ & $1.7(1)$ & $0.12(1)$ & $2.49(1)$ & $1.7(1)$ & $0.12(1)$ \\
\hline $\mathrm{O}-(\mathrm{P})-\mathrm{O}$ & $2.46(1)$ & $2.5(1)$ & $0.11(1)$ & $2.46(1)$ & $2.5(1)$ & $0.11(1)$ \\
\hline $\mathrm{O}-(\mathrm{P})-\mathrm{O}$ & $2.53(1)$ & $1.5(1)$ & $0.09(1)$ & $2.53(1)$ & $1.5(1)$ & $0.09(1)$ \\
\hline $\mathrm{O}-(\mathrm{Al})-\mathrm{O}$ & $2.65(1)$ & $0.8(1)$ & $0.12(1)$ & $2.65(1)$ & $0.8(1)$ & $0.12(1)$ \\
\hline$R-\mathrm{O}$ & $2.73(1)$ & $2.1(1)$ & $0.08(1)$ & $2.73(1)$ & $2.1(1)$ & $0.08(1)$ \\
\hline $\mathrm{P}-(\mathrm{OP})-\mathrm{O}$ & & & & $2.94(2)$ & $2.7(1)$ & $0.10(1)$ \\
\hline $\mathrm{P}-(\mathrm{O})-\mathrm{P}$ & & & & $2.98(2)$ & $2.0(1)$ & $0.10(1)$ \\
\hline$R-\mathrm{O}$ & $3.09(2)$ & $1.1(2)$ & $0.10(1)$ & & & \\
\hline$R-(\mathrm{O})-\mathrm{P}$ & $3.30(5)$ & $1.0(2)$ & $0.16(2)$ & & & \\
\hline$R-(\mathrm{O})-\mathrm{P}$ & $3.58(5)$ & $2.0(2)$ & $0.12(2)$ & & & \\
\hline
\end{tabular}

the ultraphosphates, whereas $25 \%$ are required to share in the case of the metaphosphates.

For the present $R$-Al-P-O glasses, the Al-O coordination parameters suggest that a substantial number of the $\mathrm{Al}^{3+}$ ions adopt octahedral conformations such as in crystalline ${ }^{55}$ and glassy ${ }^{25,62} \mathrm{AlP}_{3} \mathrm{O}_{9}$ where $\mathrm{Al}_{2} \mathrm{O}_{3}$ acts as a network modifier. A network modifying role for $\mathrm{Al}$ is also identified from ${ }^{17} \mathrm{Al}$ NMR studies of $\left(\mathrm{Al}_{2} \mathrm{O}_{3}\right)_{x}\left(\mathrm{P}_{2} \mathrm{O}_{5}\right)_{1-x}$ glasses with 0.319 $\leqslant x \leqslant 0.345$ which show a reduction in $\bar{n}_{\mathrm{Al}}^{\mathrm{O}}$ from 5.25(6) to 4.77(6) with increasing $x .^{63}$ The $y$ values for the $\mathrm{La} A, \mathrm{La} B$, and $\mathrm{LaCe}$ glasses were evaluated accordingly along with the $\mathrm{P}-\mathrm{O}$ and $\mathrm{O}-(\mathrm{P})-\mathrm{O}$ coordination numbers of the Hoppe and co-workers model. ${ }^{9,23-26}$ These parameters are compared, in Table IV, with those obtained from the fits to $\Delta D^{\prime}(r)$ and $D^{\prime}(r)$. The close overall agreement demonstrates that this model can act as an excellent starting point for understanding the network structure of rare-earth phosphate glasses, even when they incorporate a significant mole $\%$ of $\mathrm{Al}^{3+}$ impurity ions.

For six-fold coordinated $\mathrm{Al}$ an $\mathrm{O}_{\mathrm{T}}-(\mathrm{Al})-\mathrm{O}_{\mathrm{T}}$ coordination number of $\bar{n}_{\mathrm{O}}^{\mathrm{O}}=48 c_{\mathrm{Al}} /(5+y) c_{\mathrm{P}}$ at $\sqrt{2} r_{\mathrm{AlO}}=2.66 \AA$ is anticipated, while for tetrahedrally coordinated $\mathrm{Al}$, a coordination number of $\bar{n}_{\mathrm{O}}^{\mathrm{O}}=24 c_{\mathrm{Al}} /(5+y) c_{\mathrm{P}}$ at $\sqrt{8 / 3} r_{\mathrm{AlO}}=2.87 \AA$ is expected. The measured peak positions are given in Tables II and III and the modeled and measured $\mathrm{O}_{\mathrm{T}}-(\mathrm{Al})-\mathrm{O}_{\mathrm{T}}$ coordination numbers are compared in Table IV. Overall the diffraction data are found to be consistent with a predominantly octahedral, as opposed to tetrahedral, coordination environment for aluminum. By comparison, ${ }^{27} \mathrm{Al}$ NMR experiments made on cerium phosphate glasses of similar composition prepared in alumina crucibles show little evidence for tetrahedrally coordinated aluminum ${ }^{11}$ while those made on LaAl-P-O glasses give $\bar{n}_{\mathrm{Al}}^{\mathrm{O}} \approx 5 .{ }^{54}$ Thus the overall results for the

TABLE III. Parameters obtained from the Gaussian fits to the total pair-correlation functions $D^{\prime}(r)$ for the $\mathrm{La} A$, $\mathrm{La} B$, and $\mathrm{LaCe}$ glasses.

\begin{tabular}{|c|c|c|c|c|c|c|c|c|c|}
\hline & $\begin{array}{c}{ }^{\mathrm{La} A} D^{\prime}(r) \\
r_{\alpha \beta}(\AA)\end{array}$ & $\bar{n}_{\alpha}^{\beta}$ & $\sigma_{\alpha \beta}(\AA)$ & $\begin{array}{c}{ }^{\mathrm{La} B} D^{\prime}(r) \\
r_{\alpha \beta}(\AA)\end{array}$ & $\bar{n}_{\alpha}^{\beta}$ & $\sigma_{\alpha \beta}(\AA)$ & $\begin{array}{c}{ }^{\mathrm{LaCe}} D^{\prime}(r) \\
r_{\alpha \beta}(\AA)\end{array}$ & $\bar{n}_{\alpha}^{\beta}$ & $\sigma_{\alpha \beta}(\AA)$ \\
\hline $\mathrm{P}-\mathrm{O}_{\mathrm{T}}$ & $1.52(1)$ & $2.1(1)$ & $0.05(1)$ & $1.50(1)$ & $2.3(1)$ & $0.05(1)$ & $1.50(1)$ & $2.3(1)$ & $0.05(1)$ \\
\hline $\mathrm{P}-\mathrm{O}_{\mathrm{B}}$ & $1.61(1)$ & $1.8(1)$ & $0.11(1)$ & 1.61(1) & $1.8(1)$ & $0.10(1)$ & $1.60(1)$ & $1.8(1)$ & $0.10(1)$ \\
\hline Al-O & $1.90(3)$ & $6.0(5)$ & $0.14(2)$ & $1.89(3)$ & $6.0(5)$ & $0.10(2)$ & $1.88(3)$ & $5.5(5)$ & $0.11(2)$ \\
\hline$R-\mathrm{O}$ & $2.46(1)$ & $2.6(1)$ & $0.09(1)$ & $2.46(1)$ & $2.6(1)$ & $0.07(1)$ & $2.46(1)$ & $2.6(1)$ & $0.07(1)$ \\
\hline$R-\mathrm{O}$ & $2.50(1)$ & $1.6(1)$ & $0.12(1)$ & $2.49(1)$ & $1.7(1)$ & $0.12(1)$ & $2.49(1)$ & $1.7(1)$ & $0.12(1)$ \\
\hline $\mathrm{O}-(\mathrm{P})-\mathrm{O}$ & $2.48(1)$ & $2.4(1)$ & $0.11(1)$ & $2.46(1)$ & $2.5(1)$ & $0.11(1)$ & $2.46(1)$ & $2.5(1)$ & $0.11(1)$ \\
\hline $\mathrm{O}-(\mathrm{P})-\mathrm{O}$ & $2.53(1)$ & $1.4(1)$ & $0.06(1)$ & $2.53(1)$ & $1.5(1)$ & $0.09(1)$ & $2.53(1)$ & $1.5(1)$ & $0.09(1)$ \\
\hline $\mathrm{O}-(\mathrm{Al})-\mathrm{O}$ & $2.67(1)$ & $0.7(1)$ & $0.10(1)$ & $2.65(1)$ & $0.8(1)$ & $0.12(1)$ & $2.65(1)$ & $0.8(1)$ & $0.12(1)$ \\
\hline$R-\mathrm{O}$ & $2.75(1)$ & $2.0(1)$ & $0.08(1)$ & $2.73(1)$ & $2.1(1)$ & $0.08(1)$ & $2.73(1)$ & $2.1(1)$ & $0.08(1)$ \\
\hline $\mathrm{P}-(\mathrm{OP})-\mathrm{O}$ & $2.94(2)$ & $2.6(1)$ & $0.09(1)$ & $2.94(2)$ & $2.7(1)$ & $0.10(1)$ & $2.94(2)$ & $2.7(1)$ & $0.10(1)$ \\
\hline $\mathrm{P}-(\mathrm{O})-\mathrm{P}$ & $2.98(2)$ & $2.0(1)$ & $0.10(1)$ & $2.98(2)$ & $2.0(1)$ & $0.10(1)$ & $2.98(2)$ & $2.0(1)$ & $0.10(1)$ \\
\hline$R-\mathrm{O}$ & $3.09(2)$ & $1.1(1)$ & $0.10(1)$ & $3.09(2)$ & $1.1(1)$ & $0.10(1)$ & $3.09(2)$ & $1.1(1)$ & $0.10(1)$ \\
\hline$R-(\mathrm{O})-\mathrm{P}$ & $3.30(5)$ & $1.0(2)$ & $0.15(2)$ & $3.30(5)$ & $1.0(2)$ & $0.15(2)$ & $3.30(5)$ & $1.0(2)$ & $0.15(2)$ \\
\hline
\end{tabular}


TABLE IV. Comparison of the parameters expected from the model, based on that of Hoppe and coworkers (Refs. 9 and 23-26), and those obtained from the Gaussian fits to $D^{\prime}(r)$ and $\Delta D^{\prime}(r)$. The modelled $\mathrm{O}-(\mathrm{Al})-\mathrm{O}$ coordination numbers, $\bar{n}_{\mathrm{O}}^{\mathrm{O}}$, correspond to octahedral conformations; the corresponding $\bar{n}_{\mathrm{O}}^{\mathrm{O}}$ for tetrahedral conformations take half these values (see the text).

\begin{tabular}{lccccc}
\hline \hline Parameter & Origin & ${ }^{\mathrm{La} A} D^{\prime}(r)$ & ${ }^{\mathrm{La} B} D^{\prime}(r)$ & ${ }^{\mathrm{LaCe}} D^{\prime}(r)$ & $\Delta D^{\prime}(r)$ \\
\hline$y$ & & 1.174 & 1.260 & 1.275 & 1.268 \\
$\bar{n}_{\mathrm{P}}$ & model & 2.17 & 2.26 & 2.28 & 2.27 \\
& fit & $2.1(1)$ & $2.3(1)$ & $2.3(1)$ & $2.2(1)$ \\
$\bar{n}_{\mathrm{P}} \mathrm{O}_{\mathrm{B}}$ & model & 1.83 & 1.74 & 1.73 & 1.73 \\
& fit & $1.8(1)$ & $1.8(1)$ & $1.8(1)$ & $1.7(1)$ \\
$\bar{n}_{\mathrm{O}}^{\mathrm{O}}[\mathrm{O}-(\mathrm{P})-\mathrm{O}]$ & model & 3.89 & 3.83 & 3.82 & 3.83 \\
& fit & $3.8(1)$ & $4.0(1)$ & $4.0(1)$ & $4.0(1)$ \\
$\bar{n}_{\mathrm{O}}^{\mathrm{O}}[\mathrm{O}-(\mathrm{Al})-\mathrm{O}]$ & model & 0.84 & 0.76 & 0.89 & 0.82 \\
& fit & $0.7(1)$ & $0.8(1)$ & $0.8(1)$ & $0.8(1)$ \\
\hline \hline
\end{tabular}

glass structure can be interpreted by using the Hoppe et al. model as a template and are consistent with a network modifying role for the $\mathrm{Al}^{3+}$ ion where its predominant function is to bridge $\mathrm{PO}_{4}$ tetrahedra via $\mathrm{O}_{\mathrm{T}}-\mathrm{Al}-\mathrm{O}_{\mathrm{T}}$ bonds, thereby strengthening ${ }^{11,12}$ the glass structure.

Karabulut et al. ${ }^{54}$ used ${ }^{27} \mathrm{Al}$ NMR to measure $\bar{n}_{\mathrm{Al}}^{\mathrm{O}}$ for two series of $\left(M_{2} \mathrm{O}_{3}\right)_{x}\left(\mathrm{P}_{2} \mathrm{O}_{5}\right)_{1-x}$ glasses where $M^{3+}$ is a modifying cation chosen to be $\mathrm{La}^{3+}, \mathrm{Al}^{3+}$, or a mixture of the two. The O:P ratio was fixed at 3.0 for series I, corresponding to $x=0.25$, or at 3.143 for series II, corresponding to $x$ $=0.30$, and the results were interpreted in terms of a preferential bonding of $\mathrm{La}^{3+}$ to $\mathrm{O}_{\mathrm{T}}$ atoms. Since the $\mathrm{La}-\mathrm{O}_{\mathrm{T}}$ coordination number is greater than the $\mathrm{Al}-\mathrm{O}_{\mathrm{T}}$ coordination number it follows, for a fixed total modifier $\left(\mathrm{La}_{2} \mathrm{O}_{3}\right.$ and $\left.\mathrm{Al}_{2} \mathrm{O}_{3}\right)$ content, that the replacement of $\mathrm{La}$ by $\mathrm{Al}$ will increase the number of $\mathrm{O}_{\mathrm{T}}$ atoms available per Al. Hence the $\mathrm{Al}-\mathrm{O}_{\mathrm{T}}$ coordination number should also increase and this trend was observed in the NMR experiments of Ref. 54. Furthermore, glasses from series II have, by comparison with those from series $\mathrm{I}$, less $\mathrm{O}_{\mathrm{T}}$ atoms available per modifier ion $\left(R^{3+}\right.$ or $\mathrm{Al}^{3+}$ ), namely, 5.33 compared with 6. Preferential bonding of $\mathrm{O}_{\mathrm{T}}$ by $R^{3+}$ ions will therefore leave less $\mathrm{O}_{\mathrm{T}}$ available for the $\mathrm{Al}^{3+}$ ions, i.e., as observed in the NMR experiments, ${ }^{54}$ the series II glasses should have reduced $\bar{n}_{\mathrm{Al}}^{\mathrm{O}}$ coordination numbers.

The Al- $\mathrm{O}_{\mathrm{T}}$ coordination number for the scenario in which there is preferential bonding of $\mathrm{O}_{\mathrm{T}}$ by $R^{3+}$ ions can be deduced as follows. The number of $\mathrm{O}_{\mathrm{T}}$ atoms available per modifier ion $\left(R^{3+}\right.$ or $\left.\mathrm{Al}^{3+}\right)$ is $2\left(c_{\mathrm{O}}-2 c_{\mathrm{P}}\right) /\left(c_{R}+c_{\mathrm{Al}}\right)$ and the proportion of these $\mathrm{O}_{\mathrm{T}}$ atoms required by $R^{3+}$ ions is $\left(1-f_{s}\right) c_{R} \bar{n}_{R}^{\mathrm{O}} /\left(c_{R}+c_{\mathrm{Al}}\right)$ where $f_{s}$ is the fraction of $\mathrm{O}_{\mathrm{T}}$ atoms bonded to $R^{3+}$ that are shared between $R$-centered coordination polyhedra. Thus the number of remaining $\mathrm{O}_{\mathrm{T}}$ atoms per $\mathrm{Al}$ can be found and for the case in which these $\mathrm{O}_{\mathrm{T}}$ atoms are not shared between other $R$ - or Al-centered coordination polyhedra (i.e., when $\mathrm{Al}-\mathrm{O}_{\mathrm{T}}-\mathrm{Al}$ or $\mathrm{Al}-\mathrm{O}_{\mathrm{T}}-R$ linkages do not occur) the $\mathrm{Al}-\mathrm{O}_{\mathrm{T}}$ coordination number becomes

$$
\bar{n}_{\mathrm{Al}}^{\mathrm{O}}=\frac{2\left(c_{\mathrm{O}}-2 c_{\mathrm{P}}\right)-\left(1-f_{s}\right) c_{R} \bar{n}_{R}^{\mathrm{O}}}{c_{\mathrm{Al}}} .
$$

When $c_{R}=0$, Eq. (15) reduces to the usual Al- $\mathrm{O}_{\mathrm{T}}$ coordination number for $\mathrm{Al}_{2} \mathrm{O}_{3}-\mathrm{P}_{2} \mathrm{O}_{5}$ glasses when $\mathrm{Al}-\mathrm{O}_{\mathrm{T}}-\mathrm{Al}$ linkages are not formed. ${ }^{63}$ In the cases of $c-R \mathrm{P}_{3} \mathrm{O}_{9}$ and $c-R \mathrm{P}_{5} \mathrm{O}_{14}, \bar{n}_{R}^{\mathrm{O}}=8$, and Eq. (15) can be solved for $f_{s}$ to give the expected values of $25 \%$ and $0 \%$, respectively. For the glasses studied in the present neutron-diffraction experiments, $\bar{n}_{R}^{\mathrm{O}}=7.5$ and the average atomic fractions are $c_{R}$ $=0.068, c_{\mathrm{Al}}=0.024, c_{\mathrm{P}}=0.220$, and $c_{\mathrm{O}}=0.688$, whereupon $f_{s}$ takes on values of $31 \%$ and $26 \%$ for $\mathrm{Al}-\mathrm{O}_{\mathrm{T}}$ coordination numbers of 6 and 5 , respectively.

Equation (15) suggests a means of quantifying the connectivity of $R$-centered coordination polyhedra for the two series of $\left(M_{2} \mathrm{O}_{3}\right)_{x}\left(\mathrm{P}_{2} \mathrm{O}_{5}\right)_{1-x}$ glasses studied by Karabulut et $a l .{ }^{54} f_{s}$ was therefore evaluated for the first series, having an O:P ratio of 3.0, using the measured $\bar{n}_{\mathrm{Al}}^{\mathrm{O}}$ from NMR along with a fixed value of $\bar{n}_{R}^{\mathrm{O}}=7.2$ taken from the neutron and $\mathrm{X}$-ray studies of Hoppe et al. ${ }^{9,53}$ on glassy $\mathrm{LaP}_{3} \mathrm{O}_{9}$. For the second series, having an O:P ratio of 3.143, the measured $\bar{n}_{\mathrm{Al}}^{\mathrm{O}}$ from NMR were again used and $\bar{n}_{R}^{\mathrm{O}}$ was fixed at the value of 7.5 found in the present work for which $\mathrm{O}: \mathrm{P}=3.12$. The results, given in Fig. 7(a), show a monotonic decrease of $f_{s}$ with increasing $\mathrm{Al}_{2} \mathrm{O}_{3}$ content that is more rapid for the first series.

For each series of glass, the intrinsic connectivity of the phosphate network is held constant, i.e., within the Hoppe et al.$^{9,23-26}$ model the $\mathrm{P}: \mathrm{O}_{\mathrm{B}}: \mathrm{O}_{\mathrm{T}}$ ratio is $2: 2: 4$ for series I and $2: 1.714: 4.571$ for series II. It is therefore of interest to find for each series the dependence of the glass transition temperature, $T_{g}$, on the type of modifying cation $\left(R^{3+}\right.$ or $\left.\mathrm{Al}^{3+}\right)$ that binds to the $\mathrm{O}_{\mathrm{T}}$ of the $\mathrm{PO}_{4}$ tetrahedra. For the $\left(M_{2} \mathrm{O}_{3}\right)_{x}\left(\mathrm{P}_{2} \mathrm{O}_{5}\right)_{1-x}$ glasses, the $\mathrm{Al}-\mathrm{O}_{\mathrm{T}}: M-\mathrm{O}_{\mathrm{T}}$ bond ratio can be calculated from the expression $c_{\mathrm{Al}} \bar{n}_{\mathrm{Al}}^{\mathrm{O}} /\left(c_{R} \bar{n}_{R}^{\mathrm{O}}+c_{\mathrm{Al}} \bar{n}_{\mathrm{Al}}^{\mathrm{O}}\right)$ and, as shown in Fig. 7(b), it is found to increase most rapidly with $\mathrm{Al}_{2} \mathrm{O}_{3}$ content for the glasses of series I. As shown in Fig. 7(c), this correlates with a more rapid rise of $T_{g}$ with $\mathrm{Al}_{2} \mathrm{O}_{3}$ content for the glasses of this series, i.e., the results are consistent with a network modifying role for $\mathrm{Al}$ in which it helps to strengthen the glass through the formation of $\mathrm{O}_{\mathrm{T}}-\mathrm{Al}-\mathrm{O}_{\mathrm{T}}$ linkages. 


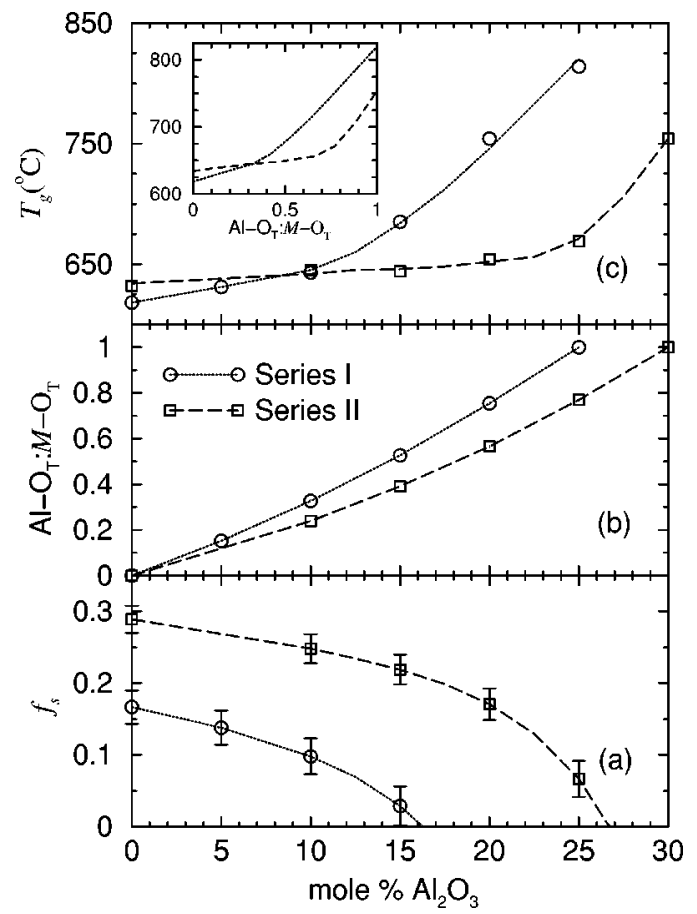

FIG. 7. For the two series of $\left(M_{2} \mathrm{O}_{3}\right)_{x}\left(\mathrm{P}_{2} \mathrm{O}_{5}\right)_{1-x}$ glasses studied by Karabulut et al. (Ref. 54), where $M^{3+}$ denotes a modifying ion $\left(\mathrm{Al}^{3+}\right.$ or $R^{3+}$ ), (a) gives the fraction, $f_{s}$, of $\mathrm{O}_{\mathrm{T}}$ atoms bonded to $R^{3+}$ that are shared between $R$-centered coordination polyhedra as calculated from Eq. (15), (b) gives the $\mathrm{Al}-\mathrm{O}_{\mathrm{T}}: M-\mathrm{O}_{\mathrm{T}}$ bond ratio according to the expression given in the text, and (c) gives the glass transition temperature, $T_{g}$. All of these parameters are plotted as a function of the $\mathrm{Al}_{2} \mathrm{O}_{3}$ content of the glasses which increases for a given series as $R_{2} \mathrm{O}_{3}$ is replaced by $\mathrm{Al}_{2} \mathrm{O}_{3}$ at a fixed total modifier $M_{2} \mathrm{O}_{3}$ content. The $f_{s}$ values and $\mathrm{Al}-\mathrm{O}_{\mathrm{T}}: M-\mathrm{O}_{\mathrm{T}}$ bond ratios are deduced using the measured $\bar{n}_{\mathrm{Al}}^{\mathrm{O}}$ values taken from the ${ }^{27} \mathrm{Al} \mathrm{NMR}$ experiments of Ref. 54 together with $\bar{n}_{R}^{\mathrm{O}}$ values fixed at either 7.2 (series I with $x=0.25$ and $\mathrm{O}: \mathrm{P}=3.0$ ) or 7.5 (series II with $x$ $=0.30$ and $\mathrm{O}: \mathrm{P}=3.143)$. The curves for $f_{s}$ and the $\mathrm{Al}-\mathrm{O}_{\mathrm{T}}: M-\mathrm{O}_{\mathrm{T}}$ bond ratios are obtained by interpolating the measured $\bar{n}_{\mathrm{Al}}^{\mathrm{O}}$, and the curves for $T_{g}$ are shown as guides for the eye. The effect of varying the $\bar{n}_{R}^{\mathrm{O}}$ values by \pm 0.2 is shown by the error bars on $f_{s}$ in (a), and it is smaller than the symbol size in (b). The inset in (c) shows the dependence of $T_{g}$ on the Al- $\mathrm{O}_{\mathrm{T}}: M-\mathrm{O}_{\mathrm{T}}$ bond ratio for both series.

By plotting $T_{g}$ for the two series as a function of the Al- $\mathrm{O}_{\mathrm{T}}: M-\mathrm{O}_{\mathrm{T}}$ bond ratio, and thereby removing its dependence with composition on the relative number of $M-\mathrm{O}_{\mathrm{T}}$ bonds formed by $\mathrm{Al}$, it is found that $T_{g}$ (series II) $>T_{g}$ (series I) for ratios $<0.33$ while $T_{g}$ (series I) $>T_{g}$ (series II) for ratios $>0.33$ [see inset in Fig. 7(c)]. This crossover of the $T_{g}$ values at $\mathrm{Al}-\mathrm{O}_{\mathrm{T}}: M-\mathrm{O}_{\mathrm{T}}=0.33$ cannot result from a change in the intrinsic connectivity of the phosphate network for a given series since this is held constant. Also, the number of $\mathrm{O}_{\mathrm{T}}$ available for bonding by the $\mathrm{M}^{3+}$ ions is fixed for a given series. Consequently, it is a moot point as to whether $T_{g}$ depends on the manner in which the network modifying cations bind to the phosphate network. Information on the latter is provided by the parameter $f_{s}$ which describes the sharing of $\mathrm{O}_{\mathrm{T}}$ by the $R$-centered coordination polyhedra. It is therefore interesting that, as shown in Fig. 7, $T_{g}$ for each series increases most rapidly with $\mathrm{Al}_{2} \mathrm{O}_{3}$ content only after $f_{s}$ has reached a small value. By comparison, the $\mathrm{Al}-\mathrm{O}_{\mathrm{T}}: M-\mathrm{O}_{\mathrm{T}}$ bond ratio for each series increases steadily with $\mathrm{Al}_{2} \mathrm{O}_{3}$ content. Hence it appears that the strengthening of $\left(M_{2} \mathrm{O}_{3}\right)_{x}\left(\mathrm{P}_{2} \mathrm{O}_{5}\right)_{1-x}$ glasses with increasing $\mathrm{Al}_{2} \mathrm{O}_{3}$ content is also dependent on the connectivity of the $R$-centered coordination polyhedra which is reduced by the replacement of $\mathrm{La}$ by Al.

It is noteworthy that $\left(M_{2} \mathrm{O}_{3}\right)_{x}\left(\mathrm{P}_{2} \mathrm{O}_{5}\right)_{1-x}$ glasses with the highest $\mathrm{Al}_{2} \mathrm{O}_{3}$ content appear to show the maximum chemical durability ${ }^{54}$ and that this correlates with minimal values of $f_{s}$, i.e., with a removal of the pathways (linked $R$-centered polyhedra) along which $R^{3+}$ ions or water molecules can presumably migrate. Small highly charged cations in phosphate glasses are also considered to strengthen the $\mathrm{P}-\mathrm{O}_{\mathrm{B}}-\mathrm{P}$ linkages and form bonds with $\mathrm{O}_{\mathrm{T}}$ that are resistant to hydration, thereby enhancing the chemical durability of the glass. ${ }^{64}$ It will be interesting to see the extent to which a polarizable, formal charge ionic interaction model can account for the observed phenomena. ${ }^{29,30}$

Finally, there is no evidence from the analysis of $\Delta D_{R}^{\prime}(r)$ for $R-R$ correlations at $r<3.5 \AA$. This is consistent with the structures of $c-\mathrm{LaP}_{3} \mathrm{O}_{9}, c-\mathrm{LaP}_{5} \mathrm{O}_{14}$, and $c-\mathrm{LaPO}_{4}$ for which the minimum La-La distance is $4.10 \AA$ (Refs. 35, 37, and 40) and with a host of other experiments on rare-earth phosphate glasses comprising large $R^{3+}$ ions. ${ }^{9,11,12,14-16}$ In the case of $R$-Al-P-O glasses comprising small rare-earth ions, a nearest-neighbor $R-R$ distance of 5.62(6) $\AA$ has recently been measured by applying the method of isomorphic substitution in neutron diffraction to glassy $R \mathrm{Al}_{0.30} \mathrm{P}_{3.05} \mathrm{O}_{9.62}$ where $R^{3+}$ denotes $\mathrm{Dy}^{3+}$ or $\mathrm{Ho}^{3+} .48$

\section{CONCLUSIONS}

The present work demonstrates that a self-consistent model, based on that of Hoppe and co-workers, ${ }^{9,23-26}$ for the structure of $R$-Al-P-O glasses comprising large rare-earth ions can be developed by applying the method of isomorphic substitution in neutron diffraction, provided that explicit account is taken of the $\mathrm{Al}$ correlations. In the case of glassy $R \mathrm{Al}_{0.35} \mathrm{P}_{3.24} \mathrm{O}_{10.12}$ it is found that a network is formed from $\mathrm{PO}_{4}$ tetrahedra in which there are, on average, 1.8(1) $\mathrm{O}_{\mathrm{B}}$ and 2.2(1) $\mathrm{O}_{\mathrm{T}}$ and the network modifying rare-earth ions bind to an average of 7.5(2) $\mathrm{O}_{\mathrm{T}}$ in a distribution that is both broad and asymmetric. A model for describing the composition dependence of the $\mathrm{Al}-\mathrm{O}_{\mathrm{T}}$ coordination number is developed using a connectivity parameter $f_{s}$ which gives the fraction of $\mathrm{O}_{\mathrm{T}}$ atoms bonded to $R^{3+}$ that are shared between $R$-centered coordination polyhedra. The model is applied to the recent ${ }^{27} \mathrm{Al}$ NMR data of Karabulut et al. ${ }^{54}$ for two series of $\left(M_{2} \mathrm{O}_{3}\right)_{x}\left(\mathrm{P}_{2} \mathrm{O}_{5}\right)_{1-x}$ glasses $(x=0.25$ and 0.30$)$ and it is shown that $f_{s}$ decreases monotonically with increasing $\mathrm{Al}$ content. The dependence on composition of $T_{g}$ is discussed and is found to increase with the $\mathrm{Al}-\mathrm{O}_{\mathrm{T}}: M-\mathrm{O}_{\mathrm{T}}$ bond ratio, most rapidly when there is a minimal connectivity of the $R$-centered coordination polyhedra. Overall, the diffraction 
and $T_{g}$ results are fully consistent with a network modifying role for the $\mathrm{Al}^{3+}$ ion in which it strengthens the glass through the formation of $\mathrm{O}_{\mathrm{T}}-\mathrm{Al}-\mathrm{O}_{\mathrm{T}}$ linkages. The chemical durability of the La-Al-P-O glasses studied in Ref. 54 also appears to be a maximum when $f_{s}$ is a minimum. The present work thereby illustrates the potential power of combined neutron-diffraction and NMR studies for describing the detailed structure of four component $R$-Al-P-O glasses and this information will, in turn, give insight into the functional properties of these materials.

*Corresponding author.

${ }^{1}$ M. J. Weber, in Materials Science and Technology, edited by J. Zarzycki (VCH, Weinheim, 1991), Vol. 9, p. 619.

${ }^{2}$ J.E. Marion and M.J. Weber, Eur. J. Solid State Inorg. Chem. 28, 271 (1991).

${ }^{3}$ C. F. Rapp, in CRC Handbook of Laser Science and Technology, Supplement 2, edited by M. J. Weber (Chemical Rubber, Boca Raton, 1995), p. 619.

${ }^{4}$ S. T. Davey, B. J. Ainslie, and R. Wyatt, in CRC Handbook of Laser Science and Technology, Supplement 2, edited by M. J. Weber (Chemical Rubber, Boca Raton, 1995), p. 635.

${ }^{5}$ C.-K. Loong, K. Suzuya, D.L. Price, B.C. Sales, and L.A. Boatner, Physica B 241-243, 890 (1998).

${ }^{6}$ R.K. Brow, J. Non-Cryst. Solids 263-264, 1 (2000).

${ }^{7}$ M. Karabulut, G.K. Marasinghe, E. Metwalli, A.K. Wittenauer, R.K. Brow, C.H. Booth, and D.K. Shuh, Phys. Rev. B 65, 104206 (2002).

${ }^{8}$ T.E. Faber and J.M. Ziman, Philos. Mag. 11, 153 (1965).

${ }^{9}$ U. Hoppe, R. Kranold, D. Stachel, A. Barz, and A.C. Hannon, J. Non-Cryst. Solids 232-234, 44 (1998).

${ }^{10}$ A. Mierzejewski, G.A. Saunders, H.A.A. Sidek, and B. Bridge, J. Non-Cryst. Solids 104, 323 (1988).

${ }^{11}$ J.M. Cole, E.R.H. van Eck, G. Mountjoy, R.J. Newport, T. Brennan, and G.A. Saunders, J. Phys.: Condens. Matter 11, 9165 (1999).

${ }^{12}$ J.M. Cole, E.R.H. van Eck, G. Mountjoy, R. Anderson, T. Brennan, G. Bushnell-Wye, R.J. Newport, and G.A. Saunders, J. Phys.: Condens. Matter 13, 4105 (2001).

${ }^{13}$ D.T. Bowron, R.J. Newport, B.D. Rainford, G.A. Saunders, and H.B. Senin, Phys. Rev. B 51, 5739 (1995).

${ }^{14}$ D.T. Bowron, G.A. Saunders, R.J. Newport, B.D. Rainford, and H.B. Senin, Phys. Rev. B 53, 5268 (1996).

${ }^{15}$ R. Anderson, T. Brennan, G. Mountjoy, R.J. Newport, and G.A. Saunders, J. Non-Cryst. Solids 232-234, 286 (1998).

${ }^{16}$ R. Anderson, T. Brennan, J.M. Cole, G. Mountjoy, D.M. Pickup, R.J. Newport, and G.A. Saunders, J. Mater. Res. 14, 4706 (1999)

${ }^{17}$ J.M. Cole, R.J. Newport, D.T. Bowron, R.F. Pettifer, G. Mountjoy, T. Brennan, and G.A. Saunders, J. Phys.: Condens. Matter 13, 6659 (2001).

${ }^{18}$ G. Mountjoy, J.M. Cole, T. Brennan, R.J. Newport, G.A. Saunders, and G.W. Wallidge, J. Non-Cryst. Solids 279, 20 (2001).

${ }^{19}$ D.T. Bowron, G. Bushnell-Wye, R.J. Newport, B.D. Rainford, and G.A. Saunders, J. Phys.: Condens. Matter 8, 3337 (1996).

${ }^{20}$ M. Cannas, E. Manca, G. Pinna, M. Bettinelli, and A. Speghini, Z. Naturforsch., A: Phys. Sci. 53, 919 (1998).

\section{ACKNOWLEDGMENTS}

It is a pleasure to thank Peter Taylor (Department of Engineering and Applied Science, Bath) for access to furnaces, Hugh Perrott (Center for Electron Optical Studies, Bath) for the electron probe micro analysis, and Pierre Palleau (ILL, Grenoble) for help with the neutron-diffraction experiments. The financial support of the EPSRC is gratefully acknowledged. This work was also supported by the Department of Energy under Contract No. W 31109 ENG 38.

${ }^{21}$ T. Moeller, The Chemistry of the Lanthanides (Pergamon, Oxford, 1973).

${ }^{22}$ A. F. Wells, Structural Inorganic Chemistry, 5th ed. (Clarendon, Oxford, 1984).

${ }^{23}$ U. Hoppe, G. Walter, and D. Stachel, Silikattechnik 41, 227 (1990).

${ }^{24}$ U. Hoppe, J. Non-Cryst. Solids 195, 138 (1996).

${ }^{25}$ U. Hoppe, G. Walter, R. Kranold, and D. Stachel, J. Non-Cryst. Solids 263-264, 29 (2000).

${ }^{26}$ U. Hoppe, H. Ebendorff-Heidepriem, J. Neuefeind, and D.T. Bowron, Z. Naturforsch., A: Phys. Sci. 56, 237 (2001).

${ }^{27}$ J.C. Wasse and P.S. Salmon, J. Phys.: Condens. Matter 11, 1381 (1999).

${ }^{28}$ J.C. Wasse, P.S. Salmon, and R.G. Delaplane, J. Phys.: Condens. Matter 12, 9539 (2000).

${ }^{29}$ F. Hutchinson, A.J. Rowley, M.K. Walters, M. Wilson, P.A. Madden, J.C. Wasse, and P.S. Salmon, J. Chem. Phys. 111, 2028 (1999).

${ }^{30}$ F. Hutchinson, M. Wilson, and P.A. Madden, Mol. Phys. 99, 811 (2001).

${ }^{31}$ R.D. Shannon, Acta Crystallogr., Sect. A: Cryst. Phys., Diffr., Theor. Gen. Crystallogr. 32, 751 (1976).

${ }^{32}$ D.G. Pettifor, J. Phys. C 19, 285 (1986).

${ }^{33}$ R.C.L. Mooney, J. Chem. Phys. 16, 1003 (1948).

${ }^{34}$ D.F. Mullica, W.O. Milligan, D.A. Grossie, G.W. Beall, and L.A. Boatner, Inorg. Chim. Acta 95, 231 (1984).

${ }^{35}$ Y. Ni, J.M. Hughes, and A.N. Mariano, Am. Mineral. 80, 21 (1995).

${ }^{36}$ H.Y.-P. Hong, Acta Crystallogr., Sect. B: Struct. Crystallogr. Cryst. Chem. 30, 468 (1974).

${ }^{37}$ J. Matuszewski, J. Kropiwnicka, and T. Znamierowska, J. Solid State Chem. 75, 285 (1988)

${ }^{38}$ H.Y.-P. Hong and J.W. Pierce, Mater. Res. Bull. 9, 179 (1974).

${ }^{39}$ M. Bagieu-Beucher and D. Tranqui, Bull. Soc. Fr. Mineral. Cristallogr. 93, 505 (1970).

${ }^{40}$ J.M. Cole, M.R. Lees, J.A.K. Howard, R.J. Newport, G.A. Saunders, and E. Schönherr, J. Solid State Chem. 150, 377 (2000).

${ }^{41}$ J.L. Yarnell, M.J. Katz, R.G. Wenzel, and S.H. Koenig, Phys. Rev. A 7, 2130 (1973).

${ }^{42}$ M.A. Howe, R.L. McGreevy, and W.S. Howells, J. Phys.: Condens. Matter 1, 3433 (1989).

${ }^{43}$ G.A. Saunders, T. Brennan, M. Acet, M. Cankurtaran, H.B. Senin, H.A.A. Sidek, and M. Federico, J. Non-Cryst. Solids 282, 291 (2001).

${ }^{44}$ C.J. Benmore and P.S. Salmon, Phys. Rev. Lett. 73, 264 (1994).

${ }^{45}$ P.S. Salmon, S. Xin, and H.E. Fischer, Phys. Rev. B 58, 6115 (1998). 
${ }^{46}$ P.S. Salmon and S. Xin, Phys. Rev. B 65, 064202 (2002).

${ }^{47}$ R. A. Martin, Ph.D. thesis, University of Bath, 2002.

${ }^{48}$ R.A. Martin, P.S. Salmon, H.E. Fischer, and G.J. Cuello, Phys. Rev. Lett. 90, 185501 (2003).

${ }^{49}$ H. Bertagnolli, P. Chieux, and M.D. Zeidler, Mol. Phys. 32, 759 (1976).

${ }^{50}$ J.F. Jal, C. Mathieu, P. Chieux, and J. Dupuy, Philos. Mag. B 62, 351 (1990).

${ }^{51}$ V.F. Sears, Neutron News 3, 26 (1992).

${ }^{52}$ D.I. Grimley, A.C. Wright, and R.N. Sinclair, J. Non-Cryst. Solids 119, 49 (1990).

${ }^{53}$ U. Hoppe, E. Metwalli, R.K. Brow, and J. Neuefeind, J. NonCryst. Solids 297, 263 (2002).

${ }^{54}$ M. Karabulut, E. Metwalli, and R.K. Brow, J. Non-Cryst. Solids 283, 211 (2001).

${ }^{55}$ H. van der Meer, Acta Crystallogr., Sect. B: Struct. Crystallogr. Cryst. Chem. 32, 2423 (1976).
${ }^{56}$ A.C. Hannon and J.M. Parker, J. Non-Cryst. Solids 274, 102 (2000).

${ }^{57}$ U. Hoppe, G. Walter, A. Barz, D. Stachel, and A.C. Hannon, J. Phys.: Condens. Matter 10, 261 (1998).

${ }^{58}$ U. Hoppe, G. Walter, R. Kranold, and D. Stachel, Z. Naturforsch., A: Phys. Sci. 53, 93 (1998).

${ }^{59}$ U. Hoppe, R. Kranold, A. Barz, D. Stachel, and J. Neuefeind, Solid State Commun. 115, 559 (2000).

${ }^{60}$ D. Stachel, I. Svoboda, and H. Fuess, Acta Crystallogr., Sect. C: Cryst. Struct. Commun. 51, 1049 (1995).

${ }^{61}$ E.H. Arbib, B. Elouadi, J.P. Chaminade, and J. Darriet, J. Solid State Chem. 127, 350 (1996).

${ }^{62}$ U. Hoppe, G. Walter, D. Stachel, and A.C. Hannon, Z. Naturforsch., A: Phys. Sci. 50, 684 (1995).

${ }^{63}$ R.K. Brow, C.A. Click, and T.M. Alam, J. Non-Cryst. Solids 274, 9 (2000).

${ }^{64}$ E. Metwalli and R.K. Brow, J. Non-Cryst. Solids 289, 113 (2001). 